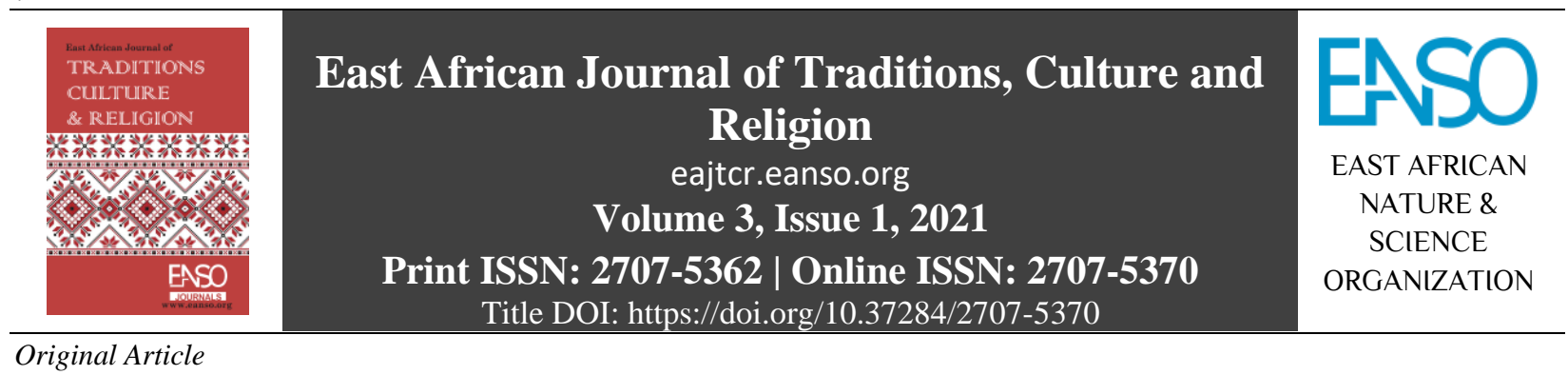

\title{
The Prospects of Integrating Traditional Religion and Orthodox Psychiatric Healing Methods Among the Baganda of Uganda.
}

\author{
Dr Hassan Lubowa Tugume, $P h D^{1^{*}}$ \\ ${ }^{1}$ Senior Lecturer, Department of Religion and Peace Studies Makerere University, P. O. Box 7062, Kampala, Uganda \\ * Author Correspondence Email: tugumelubowahassan@yahoo.com.
}

Article DOI: https://doi.org/10.37284/eajtcr.3.1.345

\section{Date Published: ABSTRACT}

15 June 2021 The main objective of this study is to analyse the possibility of integrating traditional psychiatric healing methods among the Baganda into Orthodox healing

Keywords: practices. The debate was influenced by the resistance of some ailments to the orthodox medication and the proven efficacy of traditional healing processes in the

Traditional treatment of some complications. This paper has singled out psychiatric Healing, complications. In Uganda, the ambience of psychiatric victims on the streets of Psychiatric, Kampala and towns has raised concern about the efficiency of the psychiatric Culture hospital at Butabika in Kampala. The primary data were obtained through Integration, interviews and questionnaires through a survey in five counties of Buganda Orthodox. synthesis of relevant literature on Buganda, psychiatric healing, religion and African culture. The empirical analysis was done through descriptive analysis using analytical and critical tools. This paper established that the need for alternative approaches to psychiatric cases led to new interest in traditional healing which has shown some positive responses. Consequently, traditional practitioners under their association of native healers have availed themselves the opportunity of this debate to call for recognition as partners in the provision of effective and affordable health care. This paper explored the traditional psychiatric healing process in Buganda, Uganda by analysing the various concepts, perspectives and dimensions and argued for the integration of traditional methods with modern ones.

\section{APA CITATION}

Tugume, M. O. (2021). The Prospects of Integrating Traditional Religion and Orthodox Psychiatric Healing Methods Among the Baganda of Uganda. East African Journal of Traditions, Culture and Religion, 3(1), 35-45. https://doi.org/10.37284/eajtcr.3.1.345

\section{CHICAGO CITATION}

Tugume, Hassan Lubowa. 2021. "The Prospects of Integrating Traditional Religion and Orthodox Psychiatric Healing Methods Among the Baganda of Uganda.". East African Journal of Traditions, Culture and Religion 3 (1), 35-45. https://doi.org/10.37284/eajtcr.3.1.345.

35 | This work is licensed under a Creative Commons Attribution 4.0 International License. 


\section{HARVARD CITATION}

Tugume, H. L. (2021) "The Prospects of Integrating Traditional Religion and Orthodox Psychiatric Healing Methods Among the Baganda of Uganda.", East African Journal of Traditions, Culture and Religion, 3(1), pp. 35-45. doi: 10.37284/eajtcr 3.1.345.

\section{IEEE CITATION}

H. L. Tugume, "The Prospects of Integrating Traditional Religion and Orthodox Psychiatric Healing Methods Among the Baganda of Uganda.", EAJTCR, vol. 3, no. 1, pp. 35-45 Jun. 2021.

\section{MLA CITATION}

Tugume, Hassan Lubowa. "The Prospects of Integrating Traditional Religion and Orthodox Psychiatric Healing Methods Among the Baganda of Uganda." East African Journal of Traditions, Culture and Religion, Vol. 3, no. 1, Jun. 2021, pp. 35-45, doi:10.37284/eajtcr.3.1.345.

\section{INTRODUCTION}

In the ancient cultures of the world, mainly Africa, healing involved nocturnal sacrifice, rituals and ceremonies and information, most times oral which are only known to the initiated in the art (Simians, 1957). This mode of healing raised the concern of health scientists and professionals on the principles and methods employed by local healers which are considered as lacking scientific and experimental explanations. This inexplicability of the healing processes and lack of standards, quality and control of medications stimulated suspicion among orthodox health practitioners and the diminution of the totality of the traditional religious healing process to mere fallacies or magic (Wing, 1998; Lowie, 1924).

Apart from the supernatural perspectives surrounding most of the practices, the discrepancy of the principles and methods of traditional religious healing further categorised it as destructive and unlawful in most countries of Africa, Uganda inclusive. However, the achievements of traditional health practices, effective diagnosis and treatment of some diseases where orthodox has failed and known cure by African and oriental cultures in particular China, have led to the second consideration in the utilisation of traditional healing approaches in the health care scheme. Among the traditional healing methods and practices is that of the Baganda which has enjoyed patronage from local people for the following reasons:

Absolute poverty: more than $50 \%$ of the population lives below the poverty line. Herbs are cheap and effective; most sicknesses like malaria and diarrhoea are cured by traditional medicines; and in some cases, people experience drug resistance. Consequently, even the elites who are sceptical resort to it though secretly, when western medicine offers a dim hope for their physical and spiritual wellbeing (Ssekamwa, 1991).

Conclusively, in Uganda, the high costs of primary health care and the comparative availability and affordability of traditional alternative re-invested the resort to traditional remedies by both the rich and the poor. Further, some trans-cultural scientists, medical experts and traditionalists in contemporary times have challenges that they consider as double standards in the approaches and methodologies for evaluation of orthodox and traditional medical practices (Oso ski, et.al 2002).

They argue that traditional practices should not be subjected to standards from which the orthodox system is exempted. In support, offerings and animal sacrifice were used (Patrick, 2005). To them, many healers such as the central and South American Curandero or the voodoo priests will often sacrifice an animal in the healing of illness. To the western-oriented practitioner, the very thought of this act often evokes visions of something wicked. However, from a purely ethical assessment, this practice is no different from animal experimentation conducted by contemporary medical practitioners. Most subscribers of contemporary health care would not criticise the sacrifice of a mouse to find a cure for AIDS. To a researcher, this practice should appear comparable to the Guinea pig sacrifice that Curandero perform to determine the cause and treatment of a serious illness (Wing, 1998).

The above suggests that new thinking and vista reopened by the need for a multicultural approach to medical science and research. Further, there is also new thinking that a high premium on understanding the aetiology of an ailment as a criterion for the 
acceptance of its cure and management should be de-emphasised. This paper has attempted to explore the successes of traditional religion, psychiatric healing among the Baganda, separating its repulsive and repugnant practices, highlighting its effective core and advocating for its integration into the modern system of psychological or psychiatric intervention in Uganda.

\section{METHODOLOGY}

This paper draws ten years of ethnographic participant reflection of traditional healers and their patients in five counties of Buganda, namely; Kyadondo, Buddu, Kyagwe, Mawokota and Busiro. These counties of Buganda have the highest number of native healers.

The nature of the study deserved employing mixed methods of research design. The qualitative historical approach design and observer participant were used to collect, evaluate and describe data, to explain and understand actions that were performed. It also employed a qualitative descriptive survey and used both closed and open-ended questionnaires. A purposive sampling of 124 people and selection was done. These included traditional and orthodox practitioners. It also gathered data from oral interviews from both patients and aides of traditional healers.

Medical staffs from Butabika hospital were also involved in giving their experience of dealing with drug addicts and the treatment administered to them. It was difficult to get a required sample of psychiatric patients that had gone mad as a result of drug addiction for interviews and questionnaires (Griffiths et al., 1993; Coomber, 1997).

The researcher used snowballing technique as well where necessary. This study followed research ethics to keep participants' identity and information confidential and used pseudonyms in the report (Miller et al., 2012).

Thematic analysis was used to analyse the data and respondents are quoted verbalism in the report (Attride, 2001). Finally, the work relied heavily on relevant literature from both local and western scholars, among which are cited in the reference section.

\section{FINDINGS}

The fundamental finding of this research paper is that the Baganda traditional psychiatric healing has received increased patronage in contemporary times from the Ugandan society as a result of the proven effectiveness of the practice despite the feared charms and illegal health practices associated with it. Further, there are many greedy healers who are after accumulating riches. This paper recommends the integration of traditional religion and orthodox psychiatric practices in areas of confirmed similarity in the form of assimilation, twofold consultation, for further effectiveness and expertise, while in areas that remained intractably irreconcilable, there should be partnership and complementarity.

\section{The Traditional Healers' Expertise}

Among the Baganda, every complication involved the invisible, spiritual or supernatural origins (Kaggwa, 1971; Roscoe, 1911). Hence, they are commonly perceived diseases, especially the protracted ones like insanity as dual rooted. Most traditional healers believe that "asiika obulamu tassamukono" (when saving life, negligence cannot be entertained). In any case, the supernatural and often time's long vocational and minatory preparation into the art of healing was very comprehensive and demanding. While healers are qualified by the form and nature of complaints they treat, a healer's prominence usually rests on his level of training, experience and proficiency. (Waswa \& Murima, 2006) have highlighted various classifications of healers among the Baganda and their specialist's domain of care as below;

- Traditional healer (omusawo omuganda), the general practitioner;

- Diviner (omulaguzi), Fore-tells the future;

- Herbalists (omunozi weddagala), Looks for medicine;

- Bone-setter (omuyunzi), Sets broken bones;

- Spiritualist (omumbaale), Divination and ritual expert and 
- Birth-attendant (mulerwa), Antenatal, prenatal and postnatal care

\section{Conception of Insanity (Eddalu) in Buganda}

Generally, insanity refers to odd behaviour in the household and society. While both orthodox and traditional conceptions of insanity is agreed on the pathology of insanity as well as its manifestations, loss of rationality, "a significant impairment of thought, emotional instability, distorted perception, wrong orientation and confused memory and inability to meet the ordinary demands of life" (Ofoegbu, 2005). The conception among the Baganda traditionalists transcended this (Roscoe, 1911). It was believed that the evident senselessness was only physical or human interpretation of the metaphysical inter-relation between the victim and the exerting external force or entity which surpassed the human rationality. Hence the slogan among the Baganda, ogudde ddalukuwoma mabanja" (the insane is conscious of his actions and controls his thoughts). It is also said that, Atalina manyi, taggwa ddalu (He who is weak does not run mad). While generally it was believed and in orthodox medicine that the insane or psychiatric victim murmurs some nonsense, the Baganda believe in some sense of the mad person's nonsense. This was because he was only in a state of heightened, intimate receptivity with some personalities and forces of invisible to human eyes and perception (Evans-Pritchard, 1965). In this paper, insanity, madness and psychiatric problem will be used interchangeably.

\section{Perceived Causes of Psychiatric Disorders}

In traditional Buganda, a psychiatric disorder was considered a very serious sickness. Society treated such victims as cursed and an outcast. There were many causes associated with the ailment. These could be spiritual and/or physical. Secondly, it was believed that madness was a punishment from "lubaale" (divinities) for the disobedience and dishonesty in the distant past by either the victim or his/her predecessors (Musa Kyuma (70), a traditional healer at Vuumbe in Busujju; Interviewed on April 3rd, 2015).

To some others, madness was the payment for the violations and abominations committed by one's family, clan or lineage. In this case, it was believed that the individual infected with the disorder was chosen by the "lubaale" (divinities) as the carrier for the family or as the clan might be (Musa Kyuma)

Thirdly, the ailment was also seen as the result of a failed ritual or sacrifice that went wrong either because the propitiator had no justifiable cause for the ritual or that his hands were not clean. (Bwanika Emmanuel (84), a traditional healer at Gganda in Busiro; Interviewed on June 3rd, 2014). In any case, he was ceremonially unclean to offer the ritual or appease before the higher spiritual beings that he had invoked during the operation.

While some believed that madness was genetically perpetuated hereditary (Dominic Nsubuga (94), herbalists and witch doctor at Kyamuliibwa in Buddu; Interviewed on February 3rd, 2012). Like the Luo of Kenya (Ocholla Ayayo), the Baganda believe that psychiatric disorders could be set by a wizard. Evil people within a community may direct harm to their enemies or rivals using sorcery and witchcraft. The Baganda witchcraft may be inborn, inherited or acquired by undergoing special ceremonies and rites. The wizards use specific herbs and other medicine to cause psychiatric disorders. The wizards stuff their medicine into certain material objects, dead snakes, rats, birds, chicken, rotten eggs and place these on either the farm or along the pathway of the target person. Once the latter crosses the objects, he/she runs mad (Mbiti, 1971).

Others believed the ailment resulted from disregarding warnings of the "lubaale" (divinities), hence a saying; he who the gods want to destroy, they first make him mad (interview with Bwanika Emmanuel).

Madness was also believed to be a means of executing judgment by the lubaale (divinities) through punishing the guilty party in a dispute, especially after mediation and administration of the oath that had been completed. It was believed that by the way, the guilty party was revealed and punished for his illicit atrocities against the innocent. In that situation, the victim could only regain his rationality after he had confessed his wicked deeds (Interview with Dominic Nsubuga). The above includes people who killed innocent one's in alternative ways like poisoning, bewitching, sending spells or sorcery. 
In recent times, the disease is associated with marijuana smoking which is believed to affect the brain, especially if taken by one whose brain is not developed or strong enough to withstand the effect. Marijuana is an addictive drug and once one is used to it, the abuser feels tough and strong, thus committing criminal offences like rape, defilement, robbery, and undressing etc. According to Dr. Basangwa, a Psychiatrists at the National Mental hospital at Butabika, Marijuana has an active ingredient called tetrahydro cannibal (THC) bearing a disastrous effect on the brain. It causes a disease called hallucinogen, which causes falsehood in mind. It is this incoherent mind which describes one's actions and behaviour in the long run. Field research indicated that $8 \%$ of the mental illness registered in Butabika hospital was marijuanarelated. In an interview with 200 Secondary school students in Kampala and institutions of high learning (Makerere and Kyambogo University), 3\% admitted having smoked marijuana.

Madness as a state of irrationality or insanity was believed to be of two categories; the perpetual or incurable and the transitory madness. While in most cases, these categories were determined by the magnitude of the offence that brought (Carson \& Green 1992). It was also believed that the nature of the troubling divinities also contributed to the extent of the illness (Namakula 92), an herbalist at Lwembogo in Mawogola; Interviewed on April 4th, 2014). While there were some wicked and vindictive divinities that proved very stubborn and refused to be appeased, other benevolent and kind ones were cancellable (Mbiti, 1994).

Furthermore, the Buganda traditional healers believe that no matter the cause or extent of the disease, what actually ceiled the fate of the victims or hope of healing was the nature of the effecting divinity and the traditional healer. With regards to the latter, if the victim ran away from home, great care was taken to ensure that he did not go to the streets of towns. In any case, it would mean that the victim had finally lost every cord of human reasoning, communication and fraternity and could only listen, hear and communicate with the spiritual world (akuba tembo). Hence; it was believed that if the spirits allowed the victim to heal, he would reveal information about the spiritual world. This was according to Musa Kyuma, who was reluctant to respond to the interview until permission was granted to him by his spirits.

An attempt at healing by quacks or inexperienced healers normally resulted in the death of the victim. Consequently, great care was taken by the family of the victim to guarantee that he was prevented from leaving the homestead. This was typically done by cuffing his hands and legs in severe cases or by making sure that he remained happy, calm and unprovoked. To ensure the latter, a specific member of the family who normally got along very well with the victim was given the responsibility of keeping him company, feeding him, bathing him when convenient and taking care of his general welfare; this was reflected in a Luganda slogan omulalu tabula mukwaano meaning "A mad person also has a friend." In an extreme situation when the victim proved stubborn, two or more strong men were assigned to ensure that he complied with instructions. Where this was not possible, whipping became inevitable. Surprisingly, while whipping helped to control the victim, its potency lay in its appeasing powers which calmed the victim.

\section{The Muganda Traditional Psychiatrist (Omulubaale)}

Often, the practice of healing the insane was a hereditary practice that had been preserved by the practice itself. In the family where the art dwelt, the entire family was involved. Generally, the trained personnel in the case of a nuclear family remained the leader and gave guidelines to other members. While in other families, the head of the house remained in charge of the art. In any case, the art of psychiatric healing demands both natural and supernatural powers. For the former, the knowledge of herbs, roots and other condiments necessary for the preparation of required concoctions is a requirement for success and proficiency. In this particular field, some period of training was normally required for the expert. His preparation demanded that he should be acquainted with the names and types of herbs, roots, scraps, barks of trees, parts of animals essential to the healing of disease. This was always kept top-secret from the uninitiated (Waswa \& Murima, 2006). And for the practitioners and the families, the more superiority and greater success they enjoyed over their contemporary in the art. So, excessive attention was 
taken not to divulge any family secret to other practitioners or outsiders, else the latter would render their medicine impotent, while the former would make them concede their superiority to the competitors.

The traditional Baganda believe that the art of healing is a gift from benevolent spirits, mostly bestowed to individuals who had inadvertently offered service to the spirits; others learnt the art of healing through dreams; especially the elderly (Kaggwa, 1971). In any case, tradition has been passed down. Also, the observance of taboos was necessary for the specialist to remain successful.

For mystical powers, the practitioner was expected to possess and exercise this for two reasons: It was believed that the knowledge of medicine that was used for healing surpassed human understanding and wisdom, and this could only be got by association with the spiritual world which required the possession of great supernatural influences. Secondly, for precise diagnosis of the nature and extent of the disease, the practitioner often referred to the spirits who prescribed the diagnosis. Similarly, before treatment, it was expected that the practitioner requested permission from the troubling spirit to continue in order not to incur the anger of such spirits (Lowie, 1924). Since the psychiatric patient only understood the etymological of the spirits, it was also psychiatric who could talk to him in that language. In the accurate healing, the expert sometimes invoked the assistance of the spirits by incantations. It was in the application of these miscellaneous powers, natural and supernatural skills and art that traditional healers' especially Africans, have been described as herbalists, native doctors, nature healers, traditional doctors, medicine men, witch doctors, etc.

\section{Conditions of Patients in the Healing Home}

Customarily, the healing homes comprised of many residences mostly located at the back of the homestead about 50 meters away from the family healer's house. They are built of mud, circular in shape and thatched by grass. They act as places of dwelling for the patients. The medicine and healing devices are kept in these houses as well. Usually, the healer would have some young men who were either apprentice in the art or engaged by the healer to assist him with the work. At times these young men were training in medicine. Their jobs included; slaughtering animals, looking for medicine, drumming, dancing and particularly making sure that the patients were constantly kept under control when they were not under chain (Waswa \& Murima, 2006). These young men were kins and folks of the healer to avoid an outsider from obtaining the knowledge of the art (Livingstone Lule (72), a traditional healer at Gganda in Busiro; Interviewed on June 4th, 2014).

Inside the quarter, the patients were kept in pairs according to sex. Occasionally they were untied to let them do some various tasks allocated to them by the healer; these tasks could be part of the healing process. At times the patients in the course of recovery could do some household work as chopping local medicine, cleaning the environment and often preparing food. Doing work symbolised recovery in the transition of healing (Enock Musisi (56), witchdoctor at Migamba in Mawokota; Interviewed on July 13th, 2014). Though cases and occurrences of various forms of abuses abound, extreme use of force and cruelty on the patients were common merely when patients were obstinate. Whip-strips, bruises and wounds were common sights on the patient's body. Likewise, field research established incidents of rape of female patients by their male co-inmates, the young men engaged in caring for them and even the male traditional healers who disguised to administer medicine in private parts.

\section{Admission of Psychiatric Victims into Shrines}

When a clear victim of madness was proven, the case was controlled, conferring to the nature and cause of the disease. For the perpetual cases whose causes were heinous deeds, their treatments lied with the spirits who might permit or decline his healing and in the case of the former, it prescribed the necessary treatments, which were preceded by confession to the crime in the case of an illicit deed by the victim under some supernatural influence (Mbiti, 1977).

To avert further torment and subsequent death, the healing rites were quickly inaugurated by the traditional healer. In all cases, the rites included playing the drums, dancing of the inmates, patients, 
traditional healers and his aides. Such dances in healing and spirit exorcism are usual practices in many African and Asian cultures (Wright, 1980). Others included inhaling or sipping some medication, smoking feathers of cocks and slaughtering animals. These resulted in transitory cognisance of the patient. If the spirit was benevolent, the victim might be free from all inspiration of the spirit after only that sole performance, but for the obstinate ones, the ritual might be re-enacted severally for even months before the victim finally regained freedom from the spirit (Kiwanuka Tibulisiyo (55) of Bugomola in Buddu, a herbalist; Interviewed on February $5^{\text {th }}$, 2012).

This has some implications; first, it was believed that if the patient stayed outside the healing home, he might attract the wrath of some unfriendly spirits who would want to inflict more pains and torments on the patients. Secondly, the patient was restricted to the healing home for the fear that he may attract some strange vibes which might thwart or worsen the healing process (Tadewo Nsubuga (86), a traditional healer at Gganda in Busiro; Interviewed on June 10th, 2014).

However, most families of psychiatric victims declined to admit their suffering relatives into the healing homes for fear of social stigma. The admission tantamount to admitting the insanity of their relatives could be interpreted in various ways; it could mean that the family had inherent madness. It could also mean that the insanity was a result of a horrendous deed committed by the victim or his family and was paying for it. Further, Christian priests and Muslim preachers are against the admission of any patient to the traditional healer. Very often, they boycott the victims in several ways (Juma Tomusange (88) of Vvumbe in Busujju, an herbalist; Interviewed on May 13th, 2015).

Consequently, this social stigma on the victim or his family could deny them several benefits. For the female victims, marriage became problematic as suitors and their families would not want to be related to a family of insanity. Similarly, for the male, except those who became prosperous materially, marriage for them could also be difficult. In any case, the males would not be able to attain societal status, such as acquiring titles or positions of authority in society (Nakakande Olivia (72), a herbalist at Mateete in Mawogola; Interviewed on April 13 ${ }^{\text {th }}$ 2013.)

\section{Healing Techniques of the Traditional Psychiatrist}

In Buganda traditional psychiatric healing, there were healing techniques that were peculiar. However, the common ground was that these techniques involved procedures that could be classified as having bio-psychological and religious-psychological dimensions. The former emphasises the medical values of herbs, while the latter involves the use of incantations, invocation of spiritual forces, including pouring of libations, as well as sacrifices (Arinze, 1966). Indeed, both practices are complementary. Weinberg (1964) sees this dual interpretation or conception of illness or ill-being in polarity to wellbeing so that it connotes not only physical ailment but also on a temporal and psychological dimension) present and future personal misfortune, and finally, social deviation. Upon admission into the healing home, the healer, after careful diagnosis of the causes and nature of the ailment, decided on the procedures to adopt.

In all, rest and sleep were of great importance (Nakalanzi Monica (66), a herbalist at Wakiso in Busiro; Interviewed on May 15th, 2012). Apart from keeping patients away from restlessness and mischief, it was believed that sleep and rest, especially in a serene atmosphere reinvigorated the patients and returned them to a minute level of rationality and logic (Bwanika Emmanuel). While sleep and rest were considered important curative agents, the role of music and drumming were no less significant (Masonic, 1993).

Even in orthodox practices in the west, oriental traditional cultures and practices such as Shamanism, Chakra meditation and Taoism (Mastnak, 1993) music were considered as a catalyst in the recovery process of patients. Further, its effects on the psyche are founded on a multifunctional process that includes physiological, emotional, and cognitive factors as well as an anthropological, cultural and individual condition (Mastnak, 1993).

For the Muganda traditional healer, music was of great aesthetic significance. Music was a way of

41 This work is licensed under a Creative Commons Attribution 4.0 International License. 
making the patients happy and getting the patients involved in teamwork, a substance of sanity. About the influence of music, Mastnak concluded as below: In any case, music has various influences encompassing; altered states of consciousness, modification of behaviour (when acting as reinforcement) and integration of disordered personality.

However, the choice of music for the healer was as important as its usage. There are traditional Baganda songs for twins with rhythmic, lyrical as well as responsive impacts. For the lyrical impact, the choice of soft songs with high aesthetic values: which exalt the inner beauty of the patients, their courage and positive sides normally and soothing effects on the patients and sprits (Bwanika Emmanuel).

By the rhythmic songs, the patient's senses of coordination were enforced, while the responsive impact derived from their logic and senses or reasoning were reinvigorated by the responsive nature of the songs. (Andrey Mukiibi (82), a traditional healer at Katiiti in Ssingo; Interviewed on September 13th, 2003). In such traditional practices, the employment of music therapy had been streamlined. In order to employ music in a distantly therapeutic way the issue is to discover the complex interplay of individual enculturation, life experience, physiological impact, interpretation and association, cathartic expression, and symbolic identification and creation as a process of life realisation. Their interdependence and significant balance are decisive for the result (Mastnak,1993). Similarly, the core of drumming, the complement of music in psychological healing, has equally been revealed by Sutton (1984) and Bensimon \& Wolf (2008). These demonstrate the nexus between the drumming and the inner being of man, which he identified as the soul. These exhibit the Universality of Music and drumming as therapeutic agents.

\section{Suggestions on Integration of Traditional and Orthodox Practitioners}

Since the goal of both orthodox and traditional psychiatric interventions is to achieve and maintain a satisfactory level of health care for many of the psychiatric patient population of Uganda, the need for integration, in the form of assimilation, collaboration and complementarily should be stressed.

Acknowledging the potential of traditional health practices in the health care system, especially in developing countries, World Health Organization (WHO), as early as 1978, called for the development and upgrade of traditional medicine and practice (WHO, 1978). However, while the belief in some quarters is that the outright integration of traditional and orthodox healing methods would be too ambitious and practically awkward. Others believe in their complementarity. Warren (1982) believes that there should be the integration of traditional and orthodox psychiatric practices in areas of proven similarity in the form of assimilation for further efficiency and proficiency, while in areas that remained intractably irreconcilable, there should be collaboration and complementarity. The example of theatre operation is appropriate for illustration. In an operating theatre, there will always be; the consultant surgeon, the anaesthetist, nurses etc. everybody operates within the limits of his field of proficiency, culminating in positive medical care for the patient. The operation does not consist only of cutting open the patient and removing the sick part but involves attending to the pre-surgery condition of the patient, eliminating the pains before dissection, administering drugs and injections and attending to his needs, etc.

It is the opinion of this researcher that the relationship between traditional and orthodox psychiatric practices in Uganda psychiatric intervention and general health care should be like interdependence between medical personnel in an operating theatre, collaboration and complementarity. For just as a successful surgery is not just cutting and removing sick part of the patient, successful psychiatric healing is not just returning to the sanity of the patient with drugs or concoction but also involves empirical and spiritual treatment which is all-inclusive. Moreover, counselling is essential to both traditional and orthodox healers. In all these, mutual cooperation calls for respect for each other's competence as well as recognition for individual's limitations and calls for complementarity in the areas of limitations. In Uganda, traditional psychiatric healing exists alongside orthodox practices. This is due to the 
proven effectiveness of the former. Though in some places, the traditional health services remain the only source of health care for a large number of people, it would appear that in contemporary times, patients patronised it not because of its availability or accessibility but more out of choice. Even though the elite and religious leaders who hitherto treated with contempt traditional healing practices now patronise it secretly, while the orthodox practitioners have come to appreciate the growing need for collaboration.

One of the traditional healers revealed that orthodox practitioners and religious leaders surreptitiously consult them in serious cases and in hopeless ones out rightly referred their patients to the traditional psychiatric homes (Nakato Lovinsa (58), a traditional healer Nkonge in Kyaggwe; Interviewed on August 13th, 2012). If this mutual interdependence has been established, and most Ugandans embrace these two healing methods as viable alternatives, the questions then are, why the secret relations or mutual contempt between the advocates or adherents of the two traditions. It is the submission of this research that the Ugandan government should come out with a health policy, which involves the following;

- Acknowledgement and establishing of government-run traditional psychiatric healing homes alongside the national psychiatric hospital at Butabika in Kampala;

- Reinforcement of collaboration between the traditional psychiatric healers and their orthodox psychiatric counter-parts in methodology and research;

- The government and the private sector should support researchers in traditional healing methods and remedies;

- The government and the private sector should set up a minimum of at least four psychiatric hospitals in Uganda;

- Improve the psychosocial aspects of therapy through referral of patients from traditional to cosmopolitan practitioners;

- Specific stature should be enacted to facilitate the operation of traditional medicine in Uganda and should issue such as; financing traditional medicine, quality control, chemical analysis of drugs/herbs and study their pharmacology, documentation of the therapeutic techniques used by traditional practitioners with a view of promoting those proved to be effective and developing training circular and

- Develop mechanisms and structures for regulating traditional medicine. The mechanisms and structures should include; rules of training, certificate and registration, professional, ethical standards, professional bodies and fee service structure.

\section{CONCLUSION}

Clearly, there are groups and cultures that neither comprehend ailments in a western sense nor use healing rites in a functional way similar to western therapeutic treatments. The Baganda, as demonstrated, is one of these; hence it makes sense to investigate whether the traditional psychiatric practices could be helpful in solving contemporary psychiatric problems. As this paper has attempted to do, the fundamental reasoning behind the attempt at transforming indigenous and traditional healing methods for modern psychotherapeutic purposes centres on how to reactivate those human abilities and knowledge which are stifled within our rational and profit-oriented society.

More significantly, the challenges of modern medicine make it imperative that functional practices of more than one group of specialists, traditional or orthodox, and the resource of experts from many cultures and fields, be put together for the advancement of the medical field. Indeed, the Baganda holistic bio-psychological conception of illness permits them to employ two broad points of departure to therapy. The first is bio-medical, which emphasises the healing properties of herbs, veers towards quasi-naturalism and constitutes the specialty of herbalists. The second is religionpsychological. It underscores the therapeutic force of propitiation, ritual sacrifice and incantation, and it is super naturalistic, belonging to the specialty of the fetish priest (Simans, 1957). All combine to give the patient holistic healing from within and without the body. This art of healing, therefore, has proven effective over time. 
Just like the eastern healing art of acupuncture or stylistics has been cleared of every suspicion by scientific investigation, the Baganda traditional psychiatric services should be investigated for incorporation into modern psychological or psychiatrist intervention and general health care system within and outside Uganda.

\section{REFERENCES}

Arinze, F. (1966). Sacrifice in Ibo Religion. Ibadan, Nigeria: Ibadan University Press.

Attride-Stirling, J. (2001). Thematic networks: an analytic tool for qualitative research. Qualitative Research, 1(3), 385-405.

Bensimon, M., Amir, D., \& Wolf, Y. (2008). Drumming through trauma: Music therapy with post-traumatic soldiers. The arts in psychotherapy, 35(1), 34-48.

Carson, V. B., \& Green, H. (1992). Spiritual wellbeing: A predictor of hardiness in patients with acquired immunodeficiency syndrome. Journal of professional nursing, 8(4), 209-220.

Coomber, R. (1997). The adulteration of drugs: What dealers do to illicit drugs, and what they think is done to them. Addiction Research, 5(4), 297-306.

Evans-Pritchard, E. E. (1965). Theories of primitive religion. Oxford: Clarendon Press.

Griffiths, P., Gossop, M., Powis, B., \& Strang, J. (1993). Reaching hidden populations of drug users by privileged access interviewers: methodological and practical issues. Addiction, 88(12), 1617-1626.

Ofoegbu, P. (2005) Mental Health Stresses and Migration: Celebrating Nigerian Immigrants to Connect.

Kaggwa, A. (1971). Ekitabo Kyempisa za Baganda (The customs of the Baganda) in Luganda. Nairobi: East African Publishing House.

Lowie, R. H. (1924). Primitive religion. Boni and Liveright.
Mastnak, W. (1993). Non-Western practices of healing-music and applications for modern psychotherapy. International Review of the Aesthetics and Sociology of Music, 77-84.

Mbiti.J.(1977). Introduction to African Religion. Heinemann Publishers.

Miller, T., Birch, M., \& Mautner, M. \&Jessop, J. (eds). (2012). Ethics in qualitative research. Sage

Offiong, D. A. (1999). Traditional healers in the Nigerian health care delivery system and the debate over integrating traditional and scientific medicine. Anthropological Quarterly, 118-130.

Patrick, D. (2005). Language rights in Indigenous communities: The case of the Inuit of Arctic Québec 1. Journal of Sociolinguistics, 9(3), 369389.

Roscoe, J. (1911). The customs of the Baganda. New York, NY: Columbia University Press.

Simons, H. J. (1957). Tribal medicine: diviners and herbalists. African Studies, 16(2), 85-92.

Ssekamwa, J.C. (1991). Enkuluze yeddini ya Baganda eyennono (The source of the Native Religion of the Baganda). Kampala: Woodland Printers and Stationers.

Sutton, K. (1984). The development and implementation of a music therapy physiological measures test. Journal of Music Therapy, 21(4), 160-169.

Warren, C. A. (1983). The politics of trouble in an adolescent psychiatric hospital. Urban Life, 12(3), 327-348.

Waswa, A. \&Murima, H. F. (2006). Unveiling Witchcraft. Kisubi, Uganda: Marianum Press.

Weinberg, S. K. (1964). "Mental Healing" and Social Change in West Africa. Social Problems, 11(3), 257-269.

Wing, D. M. (1998). A comparison of traditional folk healing concepts with contemporary healing concepts. Journal of Community Health Nursing, 15(3), 143-154. 
East African Journal of Traditions, Culture and Religion, Volume 3, Issue 1, 2021

Article DOI: https://doi.org/10.37284/eajtcr.3.1.345

World Health Organization. (1978). Primary Health Care Report of the International Conference Primary Health Care. Alma Ata USSR WHO, Geneva.

Wright, B. S. (1980). Dance is the cure: The arts as metaphor for healing in Kelantanese Malay spirit exorcisms. Dance research journal, 12(2), 3-10.

45 | This work is licensed under a Creative Commons Attribution 4.0 International License. 